\title{
Revisão no Campo: O Processo de Ensino-Aprendizagem dos Conceitos Ácido e Base entre 1980 e 2014
}

\section{A review of the teaching and learning approach of the acid and base concepts between 1980 and 2014}

\author{
Albino Oliveira Nunes, Josivânia Marisa Dantas, Ótom Anselmo de Oliveira e Fabiana Roberta G. e Silva \\ Hussein
}

\begin{abstract}
Resumo: Ácido e base são conceitos muito antigos, cuja origem se confunde com a própria origem da química e para os quais, ao longo dos séculos, foram propostas novas teorizações. Neste artigo, apresenta-se uma revisão sobre a abordagem de ácidos e bases em periódicos classificados nos estratos superiores do Qualis nas áreas de ensino e educação. Para tanto, foram selecionados os artigos que abordam o processo de ensino-aprendizagem desses conceitos em 16 periódicos entre 1980 e 2014, categorizando-os por análise de conteúdo. Os resultados mostram que cada periódico possui um estilo de publicação, percebendo-se que os textos publicados em periódicos brasileiros se concentram em propostas experimentais, enquanto os demais apresentam maior diversidade de abordagem didática. Em oposição, um aspecto compartilhado entre os periódicos é a predominância de artigos sobre os conceitos de Arrhenius ou Bronsted-Lowry e a pouca presença de propostas que abordem aspectos sociais, ambientais e tecnológicos.
\end{abstract}

Palavras-chave: revisão no campo, ensino-aprendizagem, ácidos e bases, abordagem de conceitos

\begin{abstract}
Acid and Base are very old concepts, whose origin intertwine with Chemistry's itself, and for which, through the ages, were proposed many new theorizations. This article presents a review on the approach on acids and bases in national and international journals classified in the higher range of Qualis in the areas of Teaching and Education. Therefore, there was a selection of papers that approach the teaching and learning of this concepts in sixteen journals dated between 1980 and 2014, categorizing them by content analysis. The results show that each journal possesses a style on publishing, realizing that Brazilian journals focus on experimental proposals, while the others show bigger diversity on didactic approach. However, a shared aspect between the journals is the prevalence of articles regarding the Arrhenius or Bronsted-Lowry concepts and the lack of presence of proposals addressing social, environmental and technological aspects.
\end{abstract}

Keywords: Review, Teaching and Learning, Acid and base, Concepts approach

\footnotetext{
Albino Oliveira Nunes (albino.nunes@ ifrn.edu.br), licenciado em química (UERN), mestre em Ensino de Ciências e Matemática, doutor em Química (Ensino de Química) (UFRN), é docente do IFRN/Campus Mossoró. Mossoró, RN - BR. Josivânia Marisa Dantas (josivaniamd@ yahoo.com.br), licenciada em Química, mestre em Físico-Química (UFRN), doutora em Ciências (UNICAMP), é docente do Centro de Educação da UFRN. Natal, RN - BR. Ótom Anselmo de Oliveira (otom@ufrnet.br), graduado em Farmácia (UFRN), doutor em Química (UNICAMP), é docente da UFRN. Natal, RN - BR. Fabiana Roberta Gonçalves e Silva (fabianah@utfpr.edu.br), bacharel em Química, doutora em Química (UFPE), pós-doutora pelo Institut de Chimie Minérale et Analytique da Université de Lausanne (Suíça), é docente da UTFPR. Curitiba, PR - BR.
}

Recebido em 16/08/2015, aceito em 12/02/2016

A seção "Cadernos de Pesquisa" é um espaço dedicado exclusivamente para artigos inéditos (empíricos, de revisão ou teóricos) que apresentem profundidade teórico-metodológica, gerem conhecimentos novos para a área e contribuições para o avanço da pesquisa em Ensino de Química. 
Ácidos e bases são conceitos ${ }^{1}$ de especial interesse na química, cuja história remonta a períodos anteriores à própria institucionalização dessa ciência, e que, ao longo do tempo, têm sido definidos a partir de diferentes referenciais químicos.

Assim como salientam Silva e Santiago (2012), substâncias ácidas e básicas já eram conhecidas pelos egípcios na Antiguidade, que dominavam a fermentação alcoólica e acética para a produção de vinho e vinagre.

Segundo Szabadvary (1966), o único ácido conhecido pelos povos da antiguidade (período pré-helênico) era o acético, enquanto os únicos álcalis eram a cal e os hidróxidos de metais alcalinos, produzidos a partir da caustificação da soda ou potassa. Nesse período, também se produzia potassa a partir de cinzas vegetais e se utilizava o ácido acético para a produção de acetatos de metais. Simultaneamente, os álcalis foram identificados com o sabor amargo presente em alguns alimentos.

Fora isso, há pouca referência aos ácidos na Antiguidade. Um exemplo é a classificação dos tipos de água que foi feita nessa época por Plínio em sulfurosas, ácidas, ferrosas e salinas (Szabadvary, 1966). Esse naturalista romano, Caio Plínio Segundo - também conhecido como Plínio, o velho -, teria vivido entre 23 e 79 d.C. Sua obra Naturalis Historia, na qual faz a menção aos tipos de águas ácidas, teria sido publicada entre 77 e 79 de nossa era.

No entanto, de onde viria a propriedade gustativa dos ácidos e álcalis, já percebida pelas civilizações antigas e usada para a sua primeira classificação? Somente muitos anos depois, chegou-se à explicação que as áreas da química e das ciências biológicas apresentam atualmente. Sobre o assunto, Retondo e Farias (2008) afirmam que a sensação de sabor está relacionada com as composições das moléculas e suas interações com receptores gustativos que se encontram distribuídos na língua, assim os seres humanos são capazes de distinguir quatro sabores básicos, o azedo, o doce, o amargo e o salgado. Sobre a relação entre a estrutura e o sabor, os autores comentam que cada sabor é evocado por uma classe característica de moléculas. Por exemplo, ao se analisar moléculas que evocam o sabor doce e amargo, podemos notar que elas são poliatômicas, e dentre os elementos que a compõem, há dois em posições próximas cujos valores de eletronegatividade são mais altos do que os dos demais elementos, sendo que um deles está diretamente ligado a um átomo do elemento hidrogênio. Já os compostos que evocam sabor azedo, em geral, são ácidos orgânicos ou inorgânicos. Por outro lado, os que evocam sabor salgado, em geral, são sais.

Particularizando o sabor ácido, Atkins (2006, p. 110) descreve a explicação atualmente aceita para esse fenômeno:
Especula-se que os botões gustativos do lado da língua contêm moléculas proteicas ricas em grupos carboxilato $\left(-\mathrm{CO}_{2}^{-}\right)$- grupos carboxílicos que perderam o íon hidrogênio; em meio ácido, são novamente convertidos a grupos carboxilas e consequentemente causam mudança na forma das moléculas de proteína, o que dispara impulsos para o cérebro.

Ainda sobre os sabores, esse autor explica que o sabor amargo é muitas vezes associado à presença de alcaloides (compostos orgânicos nitrogenados e que possuem basicidade acentuada). Nesse sentido, Retondo e Farias (2008) explicam que a diferença entre compostos que provocam o sabor doce e o amargo está no tipo de ligação de hidrogênio estabelecida entre os compostos e os receptores. Quando a ligação entre o hidrogênio do composto e o átomo de alta eletronegatividade do receptor tem intensidade próxima à da ligação entre o hidrogênio do receptor com o átomo de alta eletronegatividade do composto, sente-se o sabor doce. Quando há uma diferença acentuada entre as intensidades de ligação, em função de diferenças de eletronegatividade, o sabor percebido é o amargo.

Dessa forma, o paladar configurou-se como uma primeira possibilidade de classificação das substâncias entre essas duas classes de compostos. No entanto, o conhecimento sobre tais classes foi progressivamente incrementado ao longo da Idade Média pelos estudos alquímicos. Enquanto os alquimistas árabes tinham particular conhecimento sobre os ácidos fracos de origem orgânica, os alquimistas europeus começaram, a partir do século XIII, a isolar e utilizar os ácidos minerais, sendo o primeiro deles o ácido nítrico, obtido a partir da destilação de salitre (nitrato de sódio e potássio), seguido pelo óleo de vitríolo, nome original do ácido sulfúrico, gerado pela destilação de sulfatos metálicos (sulfato de cobre, o vitríolo azul - sulfato de alumínio e potássio, ou alúmen) (Frunz, 1989).

É importante ressaltar que, nesse período, a maior parte das informações e elaborações teóricas eram feitas por alquimistas e, a depender do período e da localidade, os escritos eram redigidos com forte conteúdo místico e com linguagem metafórica, o que dificulta sua compreensão. Apesar disso, encontram-se já no início da Idade Média referências aos ácidos e álcalis como nos escritos de Olympiodoros ao referir-se ao nitronoil, que teria a capacidade de dissolver metais, o que seria condizente com o comportamento do ácido nítrico (Szabadvary, 1966).

Há ainda uma questão relevante a se analisar do ponto de vista da história dos ácidos e bases na Idade Média. Três das mais importantes substâncias descobertas nesse período (o ácido nítrico, o ácido sulfúrico e a água régia) estão presentes no livro Summa perfectionis magisterii do alquimista árabe Jâbir Ibn

\footnotetext{
${ }^{1}$ No escopo desse artigo optou-se pelo termo conceito em detrimento de teoria e definição para referir-se a ácidos e bases. Tem-se conhecimento que outros autores usam termos distintos tais como Chagas (1999) ao referir-se às teorias ácido-base do século XX, mas no contexto desse trabalho, acredita-se ser mais adequada a caracterização como conceito. Para tanto, usamos a definição de conceito segundo o descrito por Ribeiro e Nuñez (2004) ao referirem-se a este como uma classe logicamente definida.
} 
Hayyân (Geber - na forma latinizada). Esse alquimista teria vivido entre o século VIII e IX, contudo não há registro da versão original do livro, e as primeiras referências a ele datam do século XIII. Assim, especula-se que o livro seja na verdade fruto dos trabalhos de vários alquimistas europeus que publicaram suas invenções sob um nome conhecido para dar maior projeção ou para fugir à proibição da igreja católica às práticas alquimistas.

$\mathrm{O}$ fato é que esses ácidos ganham destaque nesse período histórico em função das propriedades de dissolver metais. Como destaca Greenberg (2007), a água régia tem a propriedade de dissolver ouro e permitir sua recuperação depois.

Anos mais tarde, no século XVII, surge uma das primeiras tentativas de teorizar os conceitos de ácido e base, feita por Johann Baptista Van Helmont (1579-1644) em um sistema holístico cujo objetivo era unificar por meio de analogias os conhecimentos alquímicos e fisiológicos (Silva; Santiago, 2012; Greenberg, 2009).

Esse esforço está registrado nos estudos médicos de Van Helmont que foram publicados postumamente por seu filho com o título de Ortus medicinae (1648). Essa obra trazia várias considerações a respeito dos ácidos como, entre elas, o reconhecimento de um ácido e da bile na digestão e o papel de um ácido na inflamação e produção do pus (Greenberg, 2009).

Contudo, outro alquimista, Sylvius (François Dubois) (1614-1672), propôs uma nova classificação para a bile. Segundo este, apesar de a bile apresentar um gosto ácido, ela se comporta como um álcali. Para além dessa contribuição, Sylvius imaginou a interação dos ácidos e das bases nos organismos vivos como uma batalha, uma vez que essas duas classes de compostos, quando em contato, produzem efervescência e liberam calor. Às contribuições de Sylvius, seu discípulo Otto Tachenius (1610-1680) inseriu a ideia de sal como o produto de uma reação ácido-álcali, o que representou um avanço em relação à definição meramente sensorial que havia sido proposta anteriormente (Greenberg, 2009).

No entanto, somente com Robert Boyle (1627-1691) surgiram os primeiros referenciais químicos para classificar tais compostos. Na sua obra, Reflexions upon the hypothesis of alcali and acidum, publicada em 1675, este define que substâncias ácidas eram aquelas capazes de tornar vermelho o tornassol e álcali as que tornavam azul (Szabadváry, 1964).

As primeiras conceituações que buscaram definir ácido e base com sua estrutura química são atribuídas a Antoine Lavoisier (1743-1794) que em seus estudos concluiu que as substâncias ácidas seriam portadoras do princípio oxigênio. Anos mais tarde, essa conceituação foi refutada por Claude L. Berthollet ao indicar que o ácido prússico $(\mathrm{HCN})$ não possuía oxigênio. Contudo, por se tratar de um ácido fraco, a maior parte dos químicos da época considerou que o ácido prússico não seria um ácido verdadeiro e, portanto, mantiveram sua confiança na formulação de Lavoisier. Apenas em 1810, com a argumentação de Humphry Davy sobre análises de hidrácidos, esse conceito perde adeptos.
Segue-se a isso a elaboração da teoria eletrolítica de Arrhenius, que veio a ser uma das mais conhecidas definições de ácido-base. Tal teoria recebeu contribuições de distintos cientistas como Humphry Davy, que sugeriu o hidrogênio como fator de acidez, e Jons Jacob Berzelius, que propôs um sistema dualístico, considerando que todo sal seria formado pela junção de um ácido com uma base. Essas conceituações e os estudos eletrolíticos formaram as bases para que Arrhenius viesse a propor anos depois aquela que hoje é uma das mais conhecidas conceituações para essas funções químicas (Silva; Santiago, 2012).

Por volta de 1905, E. C. Franklin e outros químicos perceberam que não apenas a água, mas outros solventes apresentavam um comportamento parecido em sua autoionização. Das observações iniciais com amônia líquida e outros solventes, surgiu a conceituação, segundo os sistemas solventes, na qual seria ácida toda substância que promovesse o aumento da concentração do cátion e básica toda substância que promovesse o aumento da concentração do ânion (Chagas, 1999), resultantes da autoionização do solvente considerado. Mesmo com essa grande contribuição, os conceitos de ácido e base permaneciam restritos à condição de existência de um solvente.

Em 1923, trabalhando de maneira independente, dois químicos (o dinamarquês Johannes Nicolaus Brønsted [1879-1947] e o físico-químico inglês Thomas Martin Lowry [1874-1936]) propuseram os conceitos referenciados à teoria protônica, em que ácido seria toda substância capaz de doar e base toda substância capaz de receber próton. Essa conceituação tinha a vantagem de independer do meio, porém era restrita aos processos em que pelo menos uma das espécies químicas dispusesse de prótons que pudessem migrar para outra espécie química. No mesmo ano, Lewis propôs, com a conceituação protônica, a do par eletrônico, que interpretava a acidez e a basicidade em termos de recepção e doação de pares de elétrons, ampliando a definição de reações ácidobase para substâncias que não continham hidrogênio em sua estrutura.

Em 1939, dois novos conceitos de ácidos e bases foram publicados. O primeiro proposto por Hermann Lux (1904-1999) e posteriormente aprimorada por Håkon Flood (1905 - 2001), diferente da proposição de Brønsted-Lowry, tinha sua ênfase no íon superóxido $\left(\mathrm{O}_{2}^{-}\right)$, sendo classificadas como ácidas as substâncias que recebem óxido, e básicas as substâncias doadoras de óxido. Segundo Chagas (1999, p. 29), esse conceito "mostrou-se bastante útil para tratar de reações envolvendo líquidos iônicos (sais e óxidos fundidos) que ocorrem na metalurgia, na fabricação de vidro e cerâmica, nos sistemas geoquímicos $[. .]$.$" .$

No mesmo ano, Michail Illyich Usanovich (1894-1981) publicou uma conceituação que inclui todos os anteriormente citados e amplia a relação das espécies químicas que podem ser classificadas como ácidas ou básicas. Por essa conceituação, Usanovich (apud Chagas, 1999, p. 29-30) 
Definia ácido como a espécie que reage com a base para formar sais, doando cátions ou aceitando ânions ou elétrons, e base como a espécie que reage com o ácido para formar sais, doando ânions ou elétrons ou combinando-se com cátions. Essas definições são de certo modo semelhantes aos conceitos de reagentes eletrofílicos e nucleofílicos de Ingold. Apesar de constar por algum tempo em vários textos, e ser eventualmente mencionada, praticamente não gerou nenhuma linha de pesquisa.

Por fim, em 1954, I. Lindqvst e V. Gutmann tentaram unificar as conceituações de Lux-Flood, a protônica e a dos sistemas solventes, propondo a teoria ionotrópica. Contudo, essa conceituação não despertou o interesse da comunidade científica nem gerou novas linhas de pesquisas.

Essas particularidades tornam esses conceitos um tema fascinante e complexo para o processo de ensino-aprendizagem da química, uma vez que mesmo em livros voltados ao ensino superior, o uso de diferentes definições sem a explicitação para os termos ácido e base tem contribuído para dificultar a aprendizagem de estudantes em diversos níveis (Liso; Torres; Lopéz, 2002).

Neste trabalho tem-se como objetivo contribuir com a área de pesquisa em ensino de química e a prática docente ao analisar a produção em ensino-aprendizagem dos conceitos de ácido e base nos artigos publicados em periódicos da área de ensino de ciências/química no período de 1980 a 2014. Ele poderá contribuir sobremaneira para trabalhos futuros ao mapear as possibilidades dessa temática, indicando as abordagens recorrentes e as lacunas sobre o tema. Assim, pesquisadores da área poderão fazer uso desta revisão em suas investigações com o intuito de orientar suas atividades para níveis, abordagens e conceituações pouco exploradas na literatura. Em paralelo, docentes poderão fazer uso do texto como guia para a escolha de propostas e abordagens a serem utilizadas em suas salas de aula.

Destaca-se que neste trabalho foi realizada uma ampla revisão bibliográfica constituída de duas etapas: um estudo sistemático e um assistemático, de nível nacional e internacional, em periódicos, teses, dissertações e trabalhos de conclusão de curso. Entretanto, por limitação de espaço neste veículo de divulgação científica, optamos por apresentar apenas os resultados e as discussões da análise sistemática de periódicos. Além disso, nos periódicos pesquisados, foi encontrado maior número de contribuições para o campo de pesquisa.

A seguir, é apresentado o percurso metodológico adotado nessa pesquisa.

\section{Percurso metodológico}

O estudo foi desenvolvido em três etapas:

1 - Seleção dos periódicos para estudo sistemático;

2 - Seleção dos artigos nos periódicos selecionados;

3 - Seleção e categorização dos trabalhos encontrados.

Inicialmente foram selecionados 16 periódicos que constam na Tabela 1, mediante a consulta ao aplicativo WebQualis-Capes nas áreas química, ensino de ciências e educação, durante o mês de agosto de 2012. Neste mesmo ano, a classificação sofreu alterações e atualmente encontra-se diferente da apresentada. Outro parâmetro para escolha foi a disponibilidade dos periódicos, optando-se pelos de livre acesso, com exceção da revista Educación Química, que foi incluída neste estudo por sua importância na pesquisa em educação química na America Latina.

Nesses periódicos, foram analisados todos os artigos publicados desde o ano de lançamento da revista como pode ser visto na Tabela 2. No entanto, na revista Química Nova, foram

Tabela 1. Periódicos da amostra.

\begin{tabular}{lccc}
\hline Periódico/conceito Qualis & Química & Ensino & Educação \\
\hline Química Nova na Escola (Qnesc) & B3 & B1 & B2 \\
Química Nova - Seção Educação (QN) & B2 & B3 & B2 \\
Educación Química (EQ) & $\mathrm{C}$ & $\mathrm{B} 1$ & $\mathrm{~B} 1$ \\
Educació Química (EdQ) & - & - & $\mathrm{B} 4$ \\
Chemistry Education Research and Practice (CERP) & - & - & $\mathrm{A} 2$ \\
Eureka (Eu) & - & $\mathrm{B} 1$ & $\mathrm{~B} 4$ \\
Ensaio (Em) & $\mathrm{C}$ & $\mathrm{A} 2$ & $\mathrm{~B} 2$ \\
Alexandria (Al) & - & $\mathrm{B} 2$ & $\mathrm{~B} 3$ \\
Ciência e Ensino (CE) & - & $\mathrm{B} 2$ & $\mathrm{~B} 2$ \\
Ciência e Cognição (CC) & $\mathrm{C}$ & $\mathrm{B} 2$ & $\mathrm{~A} 1$ \\
Enseñanza de las Ciencias (EC) & $\mathrm{C}$ & $\mathrm{C} 1$ & $\mathrm{~A} 2$ \\
Revista Electrónica de Enseñanza de las Ciencias (REEC) & $\mathrm{C}$ & $\mathrm{A} 2$ & $\mathrm{~A} 1$ \\
Ciência e Educação (CEd) & $\mathrm{C}$ & $\mathrm{A} 1$ & $\mathrm{~B} 2$ \\
Experiências em Ensino de Ciências (EEC) & $\mathrm{C}$ & $\mathrm{C} 2$ & $\mathrm{~A} 2$ \\
Investigações em Ensino de Ciências (IEC) & $\mathrm{C}$ & $\mathrm{C} 2$ & $\mathrm{~A} 2$ \\
Revista Brasileira de Pesquisa em Educação em Ciências (RBPEC) & $\mathrm{C}$ & $\mathrm{A} 2$ & \\
\hline
\end{tabular}


Tabela 2. Período, país e número de artigos.

\begin{tabular}{|c|c|c|c|}
\hline Periódico & Nacionalidade & Período Analisado & $\mathrm{N}^{\circ}$ de artigos \\
\hline Química Nova & Brasil & $1980-2014$ & 37 \\
\hline Educación Química & México & $1989-2014$ & 25 \\
\hline Chemistry Education & Inglaterra & $1997-2014$ & 12 \\
\hline Educació Química & Espanha & $2008-2014$ & 7 \\
\hline Revista Electrónica de Enseñanza de las Ciencias & Espanha & $2002-2014$ & 2 \\
\hline Investigações em Ensino de Ciências & Brasil & $1996-2014$ & 2 \\
\hline Ciência e Cognição & Brasil & 2004-2014 & 1 \\
\hline Experiências em Ensino de Ciências & Brasil & 2006-2014 & $2^{*}$ \\
\hline Revista Brasileira de Pesquisa em Educação em Ciências & Brasil & $2001-2014$ & - \\
\hline Ensaio & Brasil & $1999-2014$ & - \\
\hline
\end{tabular}

* Um dos artigos foi publicado igualmente em dois números da revista volume 7, número 3 e volume 8, número 1.

analisados apenas os artigos da seção Educação, cujo primeiro artigo data de 1980.

A escolha dos artigos ocorreu mediante a leitura de título, resumo e palavras-chave em cada artigo, nos quais foram buscadas as palavras: ácido, base, $\mathrm{pH}$, acidez, basicidade e neutralização. Os textos que apresentaram o termo equilíbrio químico foram lidos com maior detalhamento, tendo sido inseridos no estudo somente quando incluíam discussões sobre o equilíbrio ácido-base.

Por fim, procedeu-se a etapa de categorização segundo elemento de análise de conteúdo (Bardin, 1977) com categorias determinadas a priori: 1) Conceitos ácido-base utilizados; 2) Modalidade/nível de ensino a qual se destina; 3) Estratégia/ abordagem proposta para o ensino.

Essa etapa constituiu-se de uma leitura inicial flutuante sobre o corpus de análise para verificar a validade das categorias escolhidas e de uma posterior leitura aprofundada na qual se buscou identificar a presença das categorias escolhidas.

\section{Abordagens sobre ácidos e bases em periódicos selecionados}

$\mathrm{Na}$ análise sistemática nos 16 periódicos pesquisados, foram encontrados um total de 128 artigos que direta ou indiretamente abordavam os conceitos de ácidos e bases como é mostrado na Tabela 2.

Como pode ser percebido, o tema em questão é frequente nos periódicos específicos de ensino/educação química, nos quais foram encontrados 105 artigos, correspondendo a $82 \%$ das publicações referentes ao tema. Revistas gerais sobre ensino de ciências que foram incluídas no estudo apresentaram um número pequeno de publicações sobre o tema, merecendo destaque as Revistas Eureka com 8 (6,2\%) e Enseñanza de las Ciencias com o mesmo número.

No Gráfico 1, podemos ver a distribuição dos artigos por década e o número total publicado em cada periódico no período analisado.

Como se pode perceber, ao longo das últimas quatro décadas, o tema tem sido frequentemente abordado, notando-se um incremento de artigos motivado pelo surgimento de novos periódicos em cada espaço de tempo analisado.

Outra informação que se pode encontrar é que um pequeno número de revistas concentra a maior parte dos artigos sobre o tema, principalmente as revistas específicas de ensino de química.

\section{Periódicos específicos de educação química}

Dentre as revistas que compuseram a amostra, quatro merecem destaque pelo número de artigos que abordam o tema: Química Nova (37), Química Nova na Escola (24), Educación Química (25) e Chemistry Education Research and Practice (12). A seguir, são analisados os artigos publicados em cada um desses periódicos.

\section{Química Nova - Seção Educação}

A Química Nova (QN) é um reconhecido periódico da Sociedade Brasileira de Química (SBQ). Com início em 1978, essa revista apresenta como principal foco a publicação de artigos originais em todas as áreas da química.

A partir de 1980, esse periódico passa a ter uma seção denominada Educação, na qual, segundo as normas editoriais, almeja-se publicar trabalhos de pesquisa sobre o ensino de 


\section{Artigos x Décadas}

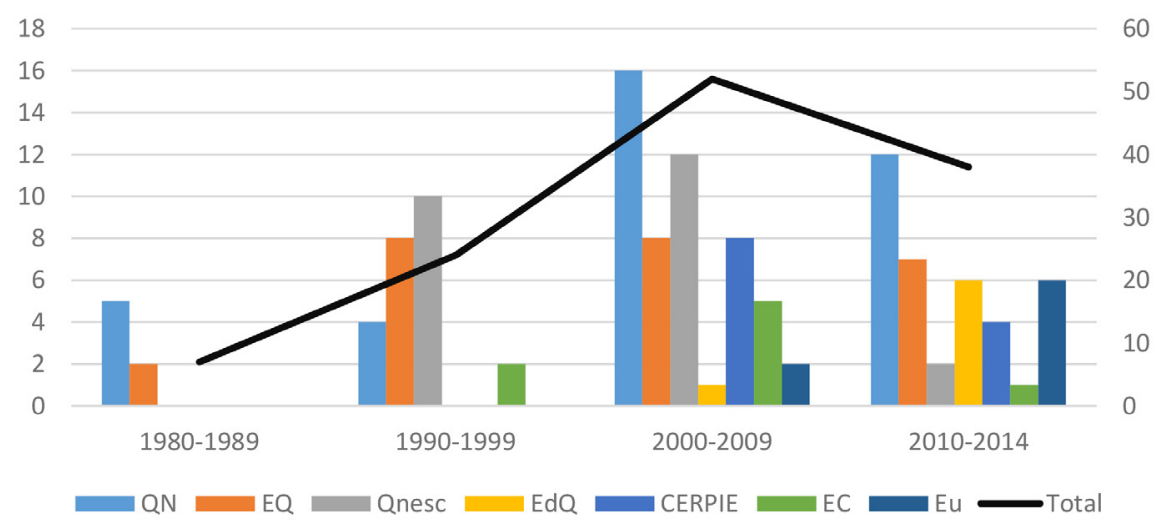

Gráfico 1. Artigos publicados sobre ácidos e bases em periódicos selecionados.

química na graduação e experiências inovadoras no ensino de graduação e pós-graduação.

Contudo, essa postura editorial parece ter sido tomada apenas alguns anos mais tarde, tendo-se em vista que, quando se analisa o público-alvo das propostas encontradas nesse periódico, apesar de notar-se a predominância de proposições para o ensino superior, que corresponde a 25 dos 32 artigos, foram encontrados três cuja temática é voltada para o ensino médio e quatro que não especificam a qual nível de ensino se destinavam.

Um aspecto relevante encontrado com base na análise de conteúdo dos artigos publicados nesse periódico é que a quase totalidade dos trabalhos não explicita a qual conceito de ácido e/ou base está se referindo, apesar de a leitura dos textos revelar que são as definições de Arrenhius e/ou Bronsted-Lowry.

Outro aspecto a ser destacado é que os únicos artigos que utilizam as definições de ácido/base propostas por Lewis são os que abordam o desenvolvimento das teorias ácido-base (Chagas, 2000; Vichi; Chagas, 2008), uma proposta de experimento (Bastos et al., 2008; Vasconcelos; Lima Júnior, 2009) e um artigo que discute a basicidade no âmbito da química orgânica (Ferreira; Arroio; Rezende, 2011). As demais definições aparecem apenas nos textos que apresentam algum caráter histórico (Chagas, 2000; Vichi; Chagas, 2008) e no texto de Vasconcellos (2014) que aborda o conceito de ácidos de Pearson para alunos da disciplina de química orgânica por meio de ferramentas computacionais.

Quanto à orientação didática das propostas, nota-se que 22 $(59,4 \%)$ dos 37 artigos apresentam propostas de experimento sem qualquer fundamentação teórica do ponto de vista didático, $7(18,9 \%)$ apresentam discussões conceituais dentro da própria química e $1(2,7 \%)$ descreve o desenvolvimento histórico das teorias. Os seis artigos que apresentam orientações didáticas têm referenciais teóricos distintos, entre os quais, vê-se referências a: contextualização, interdisciplinaridade, resolução de problemas, material didático, cotidiano e pesquisa orientada.

Deve ser enfatizado o foco principal dessa análise, cujo objetivo é compreender a abordagem usada e as contribuições oferecidas para o estudo do tema. Nesse quesito, o periódico em questão (QN) apresenta uma forte tendência à apresentação de experimentos, sem explicitar um referencial norteador ou marco teórico educacional para embasar as propostas apresentadas. Ressalta-se, no entanto, que os textos apresentam sólido embasamento em conceitos químicos (Rezende; Pizarro; Millán, 2007; Silva; Simoni, 2000; Cunha; Santana, 2012) e que são coerentes, sobretudo, com a proposta da linha editorial de publicar novas práticas no ensino superior e na pós-graduação.

\section{Química Nova na Escola}

A Química Nova na Escola (QNEsc) é outro periódico da SBQ, voltado exclusivamente para a área de educação química, objetivando fornecer os subsídios à comunidade de educadores químicos do país. Sendo publicada desde 1995, constituiu-se em um importante veículo de discussão sobre pesquisa em ensino de química no país.

Quanto à análise dos artigos publicados nesse periódico, à semelhança do que acontece na QN, na QNEsc, predominam artigos sobre experimentos. De 24 trabalhos publicados sobre a temática escolhida, 15 abordam atividades práticas em seu escopo. Contudo, há duas marcantes diferenças entre os dois periódicos: a) o primeiro volta-se predominantemente para o público do ensino superior, enquanto o segundo apresenta forte tendência para o ensino médio. Ainda que nem todos os artigos o tragam explicitamente, a leitura leva a crer que as propostas apresentadas são destinadas a esse nível de ensino; b) a maior parte dos artigos apresenta, ainda que minimamente, alguma orientação didática associada ao experimento. É o que se percebe, por exemplo, no trabalho de Maia, Gazotti e Canela (2005), em que a proposta de experimento situa-se num contexto socioambiental de discussões sobre chuva ácida.

A preocupação em apresentar experimentos com materiais alternativos, de baixo custo ou ligados ao cotidiano dos estudantes, está presente em um percentual significativo das propostas $(50 \%)$.

É nesse contexto que Suarez, Ferreira e Fatibello-Filho (2007) apresentam a padronização de uma solução básica usando o ácido 
acetilsalicílico, presente em fármacos de ação anti-inflamatória antipirética e analgésica, como padrão primário.

Destaca-se ainda a relativa importância dada ao contexto social nos artigos publicados nessa revista: com Fiorucci, Soares e Cavalheiro (2003) abordando a história, a importância e o processo industrial de obtenção da vitamina C; Fiorucci, Soares e Cavalheiro (2002) analisando o contexto histórico e social dos ácidos orgânicos; e Coelho e Marques (2007) avaliando a compreensão dos professores sobre o contexto social e visando propor uma unidade baseada em princípios da química verde para ser utilizada em programas de ensino.

No entanto, à semelhança do primeiro periódico (QN), os artigos do segundo (QNEsc) não especificam qual a compreensão de ácidos e bases é utilizada. Dentre os artigos encontrados, apenas Chagas (1999) descreve as teorias ácido-base do século XX, suas limitações e seu desenvolvimento ao longo desse período.

\section{Educación Química}

A revista Educación Química (EQ) é um periódico da Faculdade de Química da Universidad Nacional Autónoma de México com objetivos muito similares à QNEsc no tocante à pesquisa em educação química e no apoio aos docentes dessa ciência. É publicada trimestralmente desde 1989, sendo o terceiro periódico mais antigo analisado nessa pesquisa e o mais antigo dedicado exclusivamente ao ensino-aprendizagem da química.

Da análise dos artigos, percebe-se que em oposição à QNEsc e QN, a EQ apresenta um maior número de artigos conceituais e propostas que não utilizam experimentos (48\%). Nesse periódico, foram publicadas as traduções dos artigos originais nos quais Pearson descreve suas definições para ácidos duros e moles (Pearson, 1997; Pearson, 1998).

Ainda no mesmo periódico, Liso, Torres e López (2002) analisam os conceitos e as abordagens de ácidos e bases em livros de ensino secundário e ensino superior, tanto textos históricos como atuais, chegando à conclusão de que os livros-texto históricos utilizados no ensino secundário espanhol apresentavam uma abordagem mais coerente do ponto de vista conceitual. Segundo os mesmos pesquisadores, os autores dos livros (tanto históricos quanto atuais) usam os termos ácido e base indistintamente para referir-se a qualquer uma das conceituações, o que se constitui em obstáculos à aprendizagem e causa algumas dificuldades de compreensão por parte dos alunos.

Outro elemento a ser considerado nos artigos publicados na EQ é a inserção de orientações pedagógicas provenientes da pesquisa atual no campo da didática das ciências. Assim, Martinez e Espinoza (2009) utilizam mapas conceituais e a estratégia de resolução de problemas para discutir as dificuldades de aprendizagem sobre ácidos e bases. Guerra et al. (2008) apresentam uma unidade didática para ensinar tais conceitos a partir do enfoque ciência-tecnologia-sociedade (CTS) com uma orientação baseada na modelização. Cachapuz e Gonçalves (2004) apresentam uma unidade didática com orientação CTS em uma proposta de investigação-ação a partir da determinação da acidez em vinhos.

À semelhança da QN, os artigos publicados na EQ são em sua maioria voltados ao ensino superior (76\%). Observa-se ainda que, na maior parte das propostas, são usados os conceitos de ácido e base de Arrhenius e Bronsted/Lowry, ainda que em quase nenhum trabalho isso fique explícito. Exceções são os artigos de Pearson (1997; 1998) e Silva (1997), nos quais os dois primeiros tratam dos conceitos de ácidos e bases duros e moles e o terceiro traz uma proposta experimental para ensinar esses conceitos; Frunz (1989) descreve o histórico da elaboração dos diversos conceitos/definições; e Liso, Torres e López (2002) abordam os diversos conceitos ao analisarem os livros didáticos.

\section{Chemistry Education Research and Practice}

Outro periódico voltado ao ensino de química que apresenta um número significativo de artigos sobre o tema é o Chemistry Education Research and Practice (CERP), que surge da fusão, em 2005, de dois periódicos: o Chemistry Education: Research and Practice in Europe (CERPIE), publicado originalmente pela University of Ioannina (Grécia), e o University Chemistry Education, editado pela Royal Society of Chemistry (Inglaterra).

Nesse veículo, nota-se uma ênfase diferenciada em relação aos periódicos iberoamericanos por apresentar menor incidência de propostas de experimentos e uma maior diversidade de enfoques teóricos.

Sisovic e Bojovic (2000) avaliam uma proposta de aprendizagem colaborativa e diferentes formatos de trabalho em grupo, enquanto Tarhan e Sesen (2012) utilizam o jigsaw - jogo de quebra-cabeça - como estratégia de aprendizagem colaborativa para trabalhar os conceitos ácido-base com 38 estudantes do departamento de educação química da Universidade de Izmir (Turquia).

Demircioğlu, Ayas e Demircioğlu (2005) propõem uma unidade didática composta por oito aulas, visando proporcionar mudança conceitual em estudantes do ensino médio na Turquia; e Cheung (2011) apresenta em seu estudo as concepções alternativas apresentadas por licenciandos e professores de Hong Kong sobre a bateria ácida de chumbo, propondo uma atividade experimental com vistas à mudança conceitual desse público.

Drechsler e Schmidt (2005) analisam os modelos de ácido e base apresentados nos livros de química adotados para o ensino médio sueco e a compreensão dos professores de química sobre estes; e Drechsler e Driel (2009) usam uma escala de Likert para avaliar o conhecimento dos professores sobre os modelos de ácidos e bases, o conhecimento das dificuldades de aprendizagem dos estudantes e os livros usados na Suécia.

Dois outros artigos ainda trabalham na perspectiva das concepções alternativas. Sheppard (2006) entrevistou 16 
estudantes do ensino médio norte-americano sobre o entendimento de titulações ácido-base e de conceitos correlatos como pH e neutralização, enquanto Tan et al. (2010) entrevistaram 217 licenciandos em Singapura sobre seus entendimentos em relação à cinética das reações ácidas.

Pode-se ainda citar o trabalho de Bhattacharyya (2006) que, usando o model-eliciting activity, investiga os modelos mentais de 10 doutorandos em química orgânica da Universidade de Oregon sobre ácidos e bases orgânicos, focado no conceito de Bronsted-Lowry. Cita-se ainda Cartrette e Mayo (2011) que usam entrevistas com resolução de problemas para identificar a compreensão dos estudantes em cursos de química orgânica sobre ácidos e bases no contexto orgânico com ênfase no conceito elaborado por Lewis.

No tocante ao nível de ensino aos quais os trabalhos referidos nessa revista estão voltados, percebe-se uma equivalência entre o ensino médio e superior, respectivamente 60 e 50\% - um dos artigos apresenta resultados sobre os dois níveis de ensino. No entanto, o que chama mais atenção nessas publicações é que, em sua maioria, são feitas referências explícitas aos conceitos ácido-base com as quais trabalha (oito entre dez) e a preocupação em trabalhar com grupos controles para garantir a validade dos resultados apresentados quando se trata de propostas de intervenção. Esses resultados são condizentes com a linha editorial que afirma não aceitar relatos de experiência, objetivando apenas a publicação de pesquisas no âmbito da educação química com o foco no ensino-aprendizagem.

\section{Educació Química}

Fechando o ciclo de periódicos específicos de ensino de química, tem-se a Educació Química (EdQ). A mais nova dentre as revistas pesquisadas, a EdQ é um periódico publicado desde 2008 pela Societat Catalana de Química (SCQ) com objetivos muito similares aos da QNEsc.

Nessa revista catalã, foram encontrados sete artigos relativos ao tema em estudo. Dentre os quais, seis propostas de experimentos: Aymerich e Riveros (2011) apresentam resultados sobre o experimento global do $\mathrm{pH}$ da água durante o ano Internacional da Química com um grupo de estudantes espanhóis; Segura e Valls (2009) descrevem experimentos investigativos com produtos de limpeza propostos para estudantes da educação secundária; Rossi e Shimamoto (2010) propõem um experimento contextualizado com a utilização de antocianinas presentes em extratos de frutas nativas, incluindo a jussara (espécie da Mata Atlântica), para determinação de pH de uma solução; Rovira e González (2010) apresentam os resultados de uma unidade didática com estudantes do ensino técnico, na qual se buscou proporcionar o entendimento sobre a titulação ácido-base e a compreensão sobre a escolha de indicadores ácido-base para as referidas titulações; Castells (2012) apresenta uma série de atividades experimentais desenvolvidas em um curso de formação continuada para professores na Espanha; e Farusi (2012), um experimento histórico de produção de vidro para estudantes entre 14 e 15 anos de idade na Itália.

Abordagem diferente da que é feita nos demais artigos, Alvarado-Zamorano et al. (2011) apresentam uma unidade didática com enfoque Ciência-Tecnologia-Sociedade-Ambiente (CTSA) a partir do processo de acidificação dos oceanos.

Em relação ao nível a que se direcionam, apenas AlvaradoZamorano et al. (2011) e Castells (2012) voltam-se aos cursos de formação de professores de química, os demais são voltados para o ensino médio. É notório, nesses artigos, a mesma ambiguidade percebida nos periódicos anteriormente analisados no tocante a não preocupação em explicitar o conceito ácido-base implícito na proposta didática.

\section{Periódicos gerais de ensino de ciências}

Dentre as revistas gerais de educação em ciências, a Enseñanza de las Ciencias (EC) e a Eureka (Eu) são as que apresentam maior número de trabalhos envolvendo ácidos e bases, cada uma com sete artigos publicados. Todos os artigos na Eu são propostas de experimentos para trabalhar os conceitos, semelhante aos artigos apresentados pelas revistas de ensino de química brasileiras.

\section{Enseñanza de las Ciencias}

A EC é uma publicação do Institut de Ciències de l'Educació - Universitat Autònoma de Barcelona e do Vicerectorat d'investigació - Universitat de València. Tem como objetivo a publicação de investigações no âmbito das ciências naturais e matemática e teve seu primeiro número impresso em 1983 e, a partir de 2015, tornou-se exclusivamente eletrônica e de livre acesso.

Talvez por ser uma revista mais antiga e voltada ao ensino de ciências em geral, os artigos da EC apresentam maior diversidade de proposições. Assim, Borsese (1992), com ênfase completamente conceitual, trata da força de ácidos e bases; Bardaca, Nieto e Rodriguez (1993) estudam a evolução das concepções ácido-base no ensino médio no Uruguai; Torres e García (1997) propõem uma unidade didática para a aprendizagem por investigação em que os solos são tema para a aprendizagem do conceito ácido-base de Lewis; Liso et al. (2000) analisam os sentidos atribuídos ao $\mathrm{pH}$ pelos comerciais e as possíveis correlações com as concepções apresentadas por estudantes do ensino médio; Liso e Torres (2002) investigam o termo neutralização em seu sentido etimológico e os significados atribuídos ao termo ao longo da história e dentro de cada conceito ácido-base; Liso, Torres e Lopéz (2003) investigam as concepções alternativas de estudantes do ensino superior sobre o equilíbrio ácido-base, apontando que um dos problemas encontrados é o raciocínio sequencial, que provavelmente deriva da abordagem dos livros universitários; Moreno (2013) descreve o planejamento e a implementação de uma atividade de investigação orientada, contextualizada na saúde, para ensinar 
sobre soluções-tampão a alunos do ensino médio, analisando a aprendizagem dos estudantes.

\section{Eureka}

Por fim, o último periódico analisado nesse estudo é a Revista Eureka (Eu) sobre Enseñanza y Divulgación de las Ciencias, publicada desde 2004 pela Universidad de Cádiz e a Asociación de Profesores APAC-EUREKA, o que confere a revista um perfil muito próximo da escolaridade básica e de relatos de experiências.

Assim, foi observado que a Eu apresenta, em maior proporção, trabalhos voltados ao ensino médio ou pesquisas realizadas nesse nível de ensino. Nessa linha, Avalos (2006) propõe uma atividade prática com extratos naturais; Mateus et al. (2009) revisitam o mesmo tema, questionando os resultados anteriormente apresentados por Avalos; Liarte e Martínez (2011) apresentam uma proposta de atividade experimental lúdica com amônia em contato com diferentes reagentes (sulfato de cobre II, nitrato de chumbo e fenolftaleína) para demonstração com mudanças de coloração; Liarte (2010) apresenta o experimento sifão químico, no qual o ácido nítrico reage com o cobre, desencadeando a liberação de gás que posteriormente, a partir do resfriamento, é utilizado para a inversão do fluxo de líquido dentro do sifão. Ainda com a ideia de impacto visual com alterações de cor, Torres e Muñoz (2011) propõem o experimento arco-íris químico, em que uma série de reações provoca alterações na coloração de determinadas soluções, incluindo-se entre elas reações ácido-base na presença de indicadores.

Rodriguez e Bonán (2011) usam doces como matéria-prima para reações químicas, incluindo alterações de coloração quando indicadores entram em contato com os doces dissolvidos em água. $\mathrm{O}$ único artigo que apresenta um caráter diferenciado é o de Rodrigues (2011), no qual este propõe experimentos que abordem os ciclos biogeoquímicos com ênfase no tema chuva ácida.

De maneira geral, todos os artigos apresentados na Eu são da mesma natureza: experimentos voltados ao ensino médio que buscam trabalhar com materiais alternativos, sem uma preocupação maior em detalhar qual conceito ácido-base pode ser trabalhado com as práticas descritas ou sobre a orientação didático-pedagógica da proposta.

\section{Demais revistas}

As demais revistas apresentam poucos artigos sobre o tema. A Revista Eletrónica de Enseñanza de las Ciencias (REEC) publicou dois artigos no período analisado. Teixeira Júnior e Silva (2009) investigaram as dificuldades de aprendizagem de 47 licenciandos em química do estado de Minas Gerais (Brasil), concluindo que estes apresentam as mesmas dificuldades que os alunos do ensino médio. Cokelez e Dumon (2010) realizaram uma pesquisa comparativa entre os modelos de ácido e de base utilizados no ensino médio na Turquia e na França. Para tanto, realizaram um estudo com 286 estudantes franceses e 242 estudantes turcos, chegando à conclusão que o ensino francês usa preferencialmente os conceitos elaborados por Bronsted-Lowry, enquanto o sistema turco usa preferencialmente os conceitos desenvolvidos por Arrhenius.

A revista Investigações em Ensino de Ciências (IEC) apresenta dois trabalhos que versam sobre o tema: Gouveia e Valadares (2004) expõem uma discussão sobre o impacto do ambiente construtivista para a aprendizagem dos conceitos em química, descrevendo os resultados de um estudo do tipo experimental realizado com 52 estudantes do $10^{\circ}$ ano de escolaridade português, divididos em duas turmas (grupo controle e experimental). Nesse estudo, chegaram à conclusão de que um ambiente construtivista promoveu melhor aprendizagem dos conceitos ácido e base, melhorou as relações educacionais e desenvolveu atitudes positivas quanto à autoestima e interações com demais estudantes; e Pinheiro e Giordan (2010) analisaram, sob o ponto de vista da etnografia, a preparação de sabão com cinzas feitas por mulheres no interior do estado de Minas Gerais, propondo uma aproximação dos conhecimentos populares com o conhecimento dos estudantes do ensino médio, usando uma hipermídia como um elemento mediador.

Em seguida, na Tabela 3, é apresentado o perfil dos principais periódicos pesquisados.

Tabela 3. Perfil predominante dos periódicos - estudo sistemático.

\begin{tabular}{lccc}
\hline Periódico & Conceitos & Nível & Estratégia \\
\hline QN & Não explicita & Superior & $\begin{array}{c}\text { Experimentação (sem } \\
\text { fundamentação didática) }\end{array}$ \\
Qnesc & Não explicita & Médio & $\begin{array}{c}\text { Experimentação (com } \\
\text { fundamentação didática) }\end{array}$ \\
Chemistry Educ. & & & Didática das ciências \\
Educación Quim. & Explicita & Médio e superior & Didática das ciências \\
Enseñanza & Explicita & Médio e superior & Didática das ciências \\
Eureka & Explicita & Médio e superior & Experimentação (sem \\
& Não explicita & Médio & fundamentação didática) \\
Educació Química & & Experimentação (sem \\
& Não explicita & Médio & fundamentação didática) \\
\hline
\end{tabular}


Nota-se, a partir dessa tabela, que os perfis de publicação dos periódicos estão muito bem consolidados e nos indicam lacunas na pesquisa e produção nacional de conhecimento sobre o tema. A QN e QNEsc apresentam perfis complementares, estando a primeira voltada principalmente para a proposição de experimentos direcionados ao ensino superior (sem orientação didática) e a segunda, para experimentos orientados ao ensino médio. Contudo, nota-se uma ausência de pesquisas e propostas fundamentadas em outros referenciais teóricos que não a experimentação. Há que se dar destaque também à não explicitação do conceito abordado, o que não se percebe nos periódicos internacionais analisados, cuja maior parte dos artigos tem a preocupação de delimitar o conceito com o qual está trabalhando.

\section{Considerações finais}

Pelo estudo ora relatado, percebe-se que os conceitos de ácido e base são assuntos comuns na literatura específica de ensino de ciências/ensino de química. No entanto, cada periódico apresenta seu próprio perfil de publicação. Enquanto os periódicos nacionais que fizeram parte do estudo sistemático têm como foco propostas de atividades experimentais, periódicos como o Chemistry Education Research and Practice e Educación Química apresentam maior diversidade de abordagem e diferentes referenciais teóricos.

Uma constatação que cabe particularmente aos periódicos brasileiros é a falta de preocupação em delimitar os conceitos trabalhados em cada proposta, mesmo problema que tende a se repetir nos livros de ensino superior e médio. Ainda sobre essa categoria analisada, ressalta-se o pequeno número de artigos abordando os conceitos de Lewis e demais conceituações.

Nota-se que, no conjunto dos periódicos, há predominância de trabalhos para o ensino médio, seguido por trabalhos voltados ao ensino superior e a quase inexistência de trabalhos para o ensino fundamental.

No tocante ao referencial teórico, há uma grande quantidade de artigos cujo objetivo é discutir aspectos conceituais, muitas proposições de experimentos e propostas/investigações no âmbito do movimento das concepções alternativas e mudança conceitual. A concentração nesses três focos justifica-se em parte porque um dos periódicos analisados é voltado à divulgação de pesquisas na área de química (Química Nova) e não diretamente na área de ensino; e também pela própria origem da área de ensino de ciências que se consolidou em nível mundial como área de conhecimento próprio em um período de grande efervescência dos estudos em concepções alternativas, que aparecem com maior frequência em artigos mais antigos.

Por fim, o que desperta a atenção nesta revisão é a limitada ou escassa presença de discussões sobre aspectos sociais, industriais, econômicos e tecnológicos envolvendo os conceitos, a despeito de toda a influência que os ácidos e as bases possuem nesses processos. Apesar da emergência de enfoques como relações CTS, discussão de questões sociocientíficas (QSC) e abordagens em contexto no ensino de química, parece claro que esses conceitos são temas a serem ainda explorados dentro dessas perspectivas.

Ao traçar o perfil de publicação dos periódicos, no estudo tentou-se contribuir com a comunidade de educadores quími$\cos$, indicando fontes de pesquisa para a preparação de aulas, mediante os interesses específicos do docente.

Assim, o estudo demonstra que há um número significativo de propostas às quais os docentes de ensino médio e superior podem recorrer, tanto em periódicos nacionais quanto em periódicos internacionais, quando desejarem realizar uma atividade experimental sobre o tema ou para discutirem aspectos conceituais. Em paralelo, aponta lacunas importantes que emergem dessa análise e para as quais trabalhos futuros devem apontar: a) o ensino fundamental; b) conceitos de Lewis e Pearson; c) abordagem de aspectos históricos, sociais, industriais e ambientais.

\section{Referências}

ALVARADO-ZAMORANO, C.; GARRITZ, A.; GUERRA-SANTOS, G.V.; SOSA, A.M.; TERESA, C. Enseñanza y aprendizaje de ácidos y bases en contexto: acidificación de los océanos. Educació Química, n. 10, p. 4-10, 2011.

ATKINS, P.W. Moléculas. São Paulo: EdUSP, 2006.

AVALOS, S.H. Experiencias sorprendentes de química con indicadores de $\mathrm{pH}$ caseros. Revista Eureka sobre Enseñanza y Divulgación de lãs Ciencias, v. 3, n. 1, p. 89-103, 2006.

AYMERICH, M.I.; RIVEROS, B.C.L. 'aigua, sempre aigua? Una proposta indagativa per al Global Experiment de l' AIQ 2011 of the IYC 2011. Educació Química, n. 9, p. 49-57, 2011.

BARDACA, M.; NIETO, M.; RODRIGUEZ, M.C. Evolución de los conceptos ácido-base a lo largo de la ensenanza media. Enseñanza de las Ciencias, v. 11, n. 2, p. 125-129, 1993.

BARDIN, L. Análise de conteúdo. Lisboa: Edições 70, 1977.

BASTOS, R.S.; CUNHA, A.S.; SILVA, L.C.; OLIVEIRA, C.C.P.; REZENDE, C.M.; PINTO, A.C. Preparo da para-cloroanilina: um experimento simples, rápido e barato. Química Nova, v. 31, n. 1, p. 172-173, 2008.

BHATTACHARYYA, G. Practitioner development in organic chemistry: how graduate students conceptualize organic acids. Chemistry Education Research and Practice, v. 7, n. 4, p. 240, 2006.

BORSESE, A. Fuerza de los ácidos y de las bases y criterios de cálculo del ph. Enseñanza de las Ciencias, v. 10, n. 1, p. 86-88, 1992.

CACHAPUZ, A.F.; GONÇALVES, M. B. De la teoría a la práctica: la investigación/acción como estrategia para la innovación em la formación del profesorado de Química Un ejemplo em la enseñanza em laboratório del tema ácido/base. Educación Química, v. 15, n. 1, p. 8-14, 2004.

CARTRETTE, D.P.; MAYO, P.M. Students' understanding of acids/bases in organic chemistry contexts. Chemistry Education Research and Practice, v. 12, p. 29-39, 2011. 
CASTELLS, P. Els colors dels aliments. Educació Química, n. 12, p. 47-54, 2012.

CHAGAS, A.P. Teorias ácido-base do século XX. Química Nova na Escola, 1999.

CHAGAS, A.P. O ensino de aspectos históricos e filosóficos da química e as teorias ácido-base do século XX. Química Nova, v. 23, n. 2, p. 126-133, 2000.

CHEUNG, D. Using diagnostic assessment to help teachers understand the chemistry of the lead-acid battery. Chemistry Education Research and Practice, v. 12, n. 2, p. 228-237, 2011. Disponível em: <http:// xlink.rsc.org/?DOI=c1rp90028e>. Acessado em: 10 fev. 2013.

COELHO, J.C.; MARQUES, C.A. A chuva ácida na perspectiva de tema social: um estudo com professores de química. Química Nova na Escola, n. 25, p. 14-19, 2007.

COKELEZ, A.; DUMON, A. Une étude comparative des idées des élèves français et turcs sur les concepts acide et base: la transposition didactique. Revista Electrónica de Enseñanza de las Ciencias, v. 9 , n. 1, p. 67-87, 2010.

CUNHA, S.; SANTANA, L. L. B. Condensação de knoevenagel de aldeídos aromáticos com o ácido de meldrum em água: uma aula experimental de química orgânica verde. Química Nova, v. 35, n. 3, p. 642-647, 2012.

DEMIRCIOĞLU, G.; AYAS, A.; DEMIRCIOĞLU, H. Conceptual change achieved through a new teaching program on acids and bases. Chemistry Education Research and Practice, v. 6, n. 1, p. 36-51, 2005.

DRECHSLER, M.; SCHMIDT, H.J. Textbooks' and teachers' understanding of acid-base models used in chemistry teaching. Chemistry Education Research and Practice, v. 6, n. 1, p. 19, 2005. Disponível em: <http://xlink.rsc.org/?DOI=b4rp90002b>. Acessado em: 10 fev. 2013.

DRECHSLER, M.; DRIEL, J. Teachers' perceptions of the teaching of acids and bases in Swedish upper secondary schools. Chemistry Education Research and Practice, v. 10, n. 2, p. 86, 2009.

FARUSI, G. Preparazione di tessere di vetro con acido borico preparació de tessel · les de vidre amb àcid boric. Educació Química, n. 11, p. 40-44, 2012

FERREIRA, C.; ARROIO, A.; REZENDE, D. B., Uso de modelagem molecular no estudo dos conceitos de nucleofilicidade e basicidade. Química Nova, v. 34, n. 9, p. 1661-1665, 2011.

FIORUCCI, A.R.; SOARES, M.H.F.B.; CAVALHEIRO, É.T.G. Alguns ácidos orgânicos do nosso cotidiano. Química Nova na Escola, n. 15, p. 6-10, 2002.

. A importância da vitamina $\mathrm{C}$ na sociedade através dos tempos. Química Nova na Escola, n. 17, p. 3-7, 2003.

FRUNZ, J.L.C. Acidos y bases. Educación Química, p. 33-36, 1989.

GOUVEIA, V.; VALADARES, J. A aprendizagem em ambientes construtivistas: uma pesquisa relacionada com o tema ácido-base. Investigações em Ensino de Ciências, v. 9, n. 2, p. 199-220, 2004.

GREENBERG, A. From alchemy to chemistry in picture and story. Hoboken: Jonh Wiley \& Sons, 2007.

Uma breve história da química: da alquimia às ciências moleculares modernas. São Paulo: Edgard Blucher, 2009.
GUERRA, G.; ALVARADO, C.; ZENTENO-MENDOZA, B. E.; GARRITZ, A. La dimensión ciencia-tecnología-sociedaddel tema de ácidos y bases em un aula del bachillerato. Educación Química, p. 277-288, 2008.

LIARTE, D.Á.G. Un sifón a partir de una reacción química. Revista Eureka sobre Enseñanza y Divulgación de las Ciencias, v. 7, n. 1, p. 142-150, 2010.

LIARTE, D.Á.G.; MARTÍNEZ, M.P. Azul, blanco, rojo. Homenaje a Lavoisier. Revista Eureka sobre Enseñanza y Divulgación de las Ciencias, v. 8, n. extraordinario, p. 437-445, 2011.

LISO, M.R.J.; TORRES, E.D.M.; LÓPEZ, F.S. El razonamiento causal secuencial em los equilibrios ácido-base múltiples. Enseñanza de las Ciencias, v. 21, n. 2, p. 223-242, 2003.

LISO, M.R.J.; TORRES, E.M. La neutralización ácido-base. Enseñanza de las Ciencias, v. 20, n. 3, p. 451-464, 2002.

LISO, M.R.; TORRES, E.M.; LÓPEZ, F.S. Los procesos ácido-base en los textos actuales y antiguos (1868-1955). Educación Química, v. 13, n. 2, p. 90-100, 2002.

LISO, M.R.J.; TORRES, E.M.; GARCÍA, F.G.; LÓPEZ, F.S. Investigación didáctica la utilización del concepto de ph em la publicidad y su relación com las ideas que manejan los alumnos: aplicaciones em el aula. Enseñanza de las Ciencias, v. 18, n. 3, p. 451-461, 2000.

MAIA, D.J.; GAZOTTI, W.A.; CANELA, M.C. Chuva ácida: um experimento para introduzir conceitos de equilíbrio químico e acidez no ensino médio. Química Nova na Escola, n. 21, p. 44-46, 2005.

MARTÍNEZ, M.; ESPINOZA, A. Correlación entre mapas conceptuales y habilidad para la resolución de problemas em la unidad de Equilibrio Iónico em la asignatura de química general. Educación Química, v. 20, n.2, p. 198-208, 2009.

MATEUS, J.A.C.; DAZA, H.J.C.; HILARIÓN, J.M.N.; PARADA, A.N.P.; VALBUENA, R.L.R. Elaboración de papel indicador a base de extractos naturales: una alternativa fundamentada en experiencias de laboratorio para el aprendizaje del concepto de $\mathrm{pH}$. Revista Eureka sobre Enseñanza y Divulgación de las Ciencias, v. 9, n. 2, p. 302-314, 2009.

MORENO, M.T. Aprendizaje sobre disoluciones reguladoras de $\mathrm{pH}$ mediante indagación guiada utilizando sensores. Enseñanza de las ciências, v. 31, n. 1, p. 189-211, 2013.

PEARSON, R.G. Ácidos y bases duros y blandos: segunda parte, teorías suyacentes. Educación Química, v. 9, n. 2, p. 112-118, 1998.

Ácidos y bases duros y blandos * Primera parte: Principios fundamentales. Educación Química, v. 8, n. 4, p. 208-215, 1997.

PINHEIRO, P.C.; GIORDAN, M. O preparo do sabão de cinzas em Minas Gerais, Brasil: do status de etnociência à sua medição para a sala de aula utilizando um sistema hipermídia etnofigura. Investigações em Ensino de Ciências, v. 15, n. 2, p. 355-383, 2010.

RETONDO, C.G.; FARIAS, P. Química das sensações. Campinas: Átomo, 2008.

REZENDE, M.C.; PIZARRO, C.; MILlAN, D. Preparation, spectroscopic and acidity properties of two hydrazones: an organic lab experiment. Química Nova, v. 30, n. 1, p. 229-231, 2007.

RIBEIRO, R.P.; NUÑEZ, I.B. A aprendizagem significativa e o ensino 
de ciências naturais. In: NUÑEZ, I.B.; RAMALHO, B.L. (Orgs.). Fundamentos do ensino aprendizagem das ciências naturais e da matemática: o novo ensino médio. Porto Alegre: Sulina, 2004. RODRIGUES, A.P.L. De la geosfera a la biosfera : circulación de matéria em la naturaleza. Revista Eureka sobre Enseñanza y Divulgación de las Ciencias, v. 8, n. extraordinario, p. 495-499, 2011.

RODRÍGUEZ, J.M.R.; BONÁN, J.A.N.T. Aprendiendo química con golosinas. Revista Eureka sobre Enseñanza y Divulgación de lãs Ciencias, v. 8, n. extraordinario, p. 476-486, 2011.

ROSSI, A.V.; SHIMAMOTO, G. G. Antocianinas e gelo seco para visualizar equilíbrios ácido/base numa abordagem contextualizada. Educació Química, n. 7, p. 31-36, 2010.

ROVIRA, L.D.I.; GONZÁLEZ, M.P.I. Quin indicador utilitzaré en una valoració àcid-base? Educació Química, n. 7, p. 52-58, 2010.

SEGURA, M.; VALLS, J.M. Els misteris dels productes de neteja. Educació Química, n. 3, p. 4-10, 2009.

SHEPPARD, K. High school students' understanding of titrations and related acid-base phenomena. Chemistry Education Research and Practice, v. 7, n. 1, p. 32, 2006.

SILVA, L.G. Ácidos y bases duros y blandos: descubriendo el principio en el laboratorio. Educación Química, v. 8, n. 4, p. 205-207, 1997.

SILVA, M.P.; SANTIAGO, M.A. Proposta para o ensino dos conceitos de ácidos e bases: construindo conceitos através da história da ciência combinada ao emprego de um software interativo de livre acesso. História da Ciência e Ensino: Construindo Interfaces, v. 5, p. 48-82, 2012.

SILVA, C.R.; SIMONI, J.A. Avaliação da capacidade tamponante - um experimento participativo. Química Nova, v. 23, n. 3, p. 405-409, 2000.

SISOVIC, D.; BOJOVIC, S. Approaching the concepts of acids and bases by cooperative learning. Chemistry Education Research and Practice, v. 1, n. 2, p. 263-275, 2000.
SUAREZ, W.T.; FERREIRA, L.H.; FATIBELLO-FILHO, O. Padronização de soluções ácida e base empregando materiais do cotidiano. Química Nova na Escola, n. 25, p. 36-38, 2007.

SZABADVARY, F. History of analytcal chemistry. Londres: Permagom, 1966.

Development of the $\mathrm{pH}$ concept: a historical survey. Journal of Chemical Education, v. 41, n. 2, p. 105-107, 1964.

TAN, K.C.D.; TREAGUST, D.F.; CHANDRASEGARAN, A.L.; MOCERINO, M. Kinetics of acid reactions: making sense of associated concepts. Chemistry Education Research and Practice, v. 11, n. 4 , p. 267,2010

TARHAN, L.; SESEN, B. A. Jigsaw cooperative learning: acid-base theories. Chemistry Education Research and Practice, v. 13, n. 3, p. 307, 2012.

TEIXEIRA JR., J.G.; SILVA, R.M.G. Investigando a temática sobre equilíbrio químico na formação inicial docente. Revista Electrónica de Enseñanza de las Ciencias, v. 8, n. 2, p. 571-592, 2009.

TORRES, C.D.; MUÑOZ, M.L.A. Reacciones encadenadas: del reloj de yodo al arco iris químico. Revista Eureka sobre Enseñanza y Divulgación de las Ciencias, v. 8, n. 1, p. 105-110, 2011.

TORRES, L.E.S.; GARCÍA, J.J.G. Los suelos en la enseñanza de la teoría ácido-base de Lewis. Uma estratégia didáctica de aprendizaje por investigación. Enseñanza de las Ciencias, v. 15, n. 1, p. 59-71, 1997.

VASCONCELLOS, M.L.A.A. A teoria de Pearson para a disciplina de química orgânica: um exercício prático e teórico aplicado em sala de aula. Química Nova, v. 37, n. 1, p. 171-175, 2014.

VASCONCELLOS, M.L.A.A.; LIMA JR., C.G. Cloração do anisol, tolueno e nitrobenzeno com ácido tricloroisocianúrico (ATCI): aspectos computacionais sobre a reatividade e regiosseletividade. Química Nova, v. 32, n. 1, p. 244-249, 2009.

VICHI, E.J.S.; CHAGAS, A.P. Sobre a força de ácidos e bases: algumas considerações. Química Nova, v. 31, n. 6, p. 1591-1594, 2008. 